\title{
Д.А. Самойлова
}

Новосибирский государственный педагогический университет

\section{О некоторых аспектах рецепции романа «Мастер и Маргарита» в сетевой среде}

Аннотация: В данной статье, посвященной восприятию романа М. Булгакова «Мастер и Маргарита», дается краткий анализ некоторых аспектов восприятия данного текста, представленных различными категориями читателей. Исследование проводилось в сети Интернет, как среди участников специализированных форумов, так и среди случайных пользователей социальных сетей. Возрастная категория - 18-45 лет.

In given article results of poll devoted to perception of the novel by M. Bulgakov «the Master and Margarita», and also the short analysis of various aspects of perception of the given text are presented by various categories of readers. Research was spent to networks the Internet as among participants specialized forums, and social networks. An age category of recipients $-18-45$ years.

Ключевые слова: социология чтения, рецепция, возрастная категория, социальная категория.

Sociology of reading, reception, age category, social category.

УДК: 82:111.852. Эстетика литературы. Литературный вкус.

Контактная информация: Новосибирск, ул. Вилюйская, 28. НГПУ, кафедра русской литературы. E-mail: dana220@mail.ru.

В ходе исследования различных аспектов рецепции романа «Мастер и Маргарита» мы обращались к диахронному, топографическому, возрастному и гендерному аспектам читательских конкретизаций. Данная статья посвящена анализу краткого опроса, проведенного среди различных категорий читателей.

Не секрет, что Интернет прочно вошел в обиход подавляющего числа образованных россиян. Мы обратились к пользователям всемирной паутины с просьбой заполнить небольшую анкету, позволяющую выявить культурноисторические и индивидуальные (личностные) аспекты каждого конкретного восприятия и его пролонгированность во времени.

Для проведения опроса использовались специализированные форумы, посвященные творчеству М. Булгакова («Однажды на Патриарших», «Великий Мастер на сцене и за кулисами», «Булгаковский дом» и др.). Принимали участие в нем и случайно избранные пользователи социальных сетей («В контакте», «Мой мир» и пр.). В целом, процент откликнувшихся достаточно велик (на 100 предложений заполнить анкету - всего 15 отказов). Среди участников специализированных булгаковских форумов отказов не наблюдалось. Напротив, мы не единожды встретились с мнением, что в короткой анкете невозможно передать всю гамму ощущений, навеянных романом и его перечитыванием. Зачастую мы получали целые эссе на заданную тему. Участники опроса, что примечательно, предлагали свою помощь в составлении анкет, а также в проведении исследования. Таким образом, роман относится к числу произведений, стимулирующих читательскую активность и образование читательских сообществ. 
Наш опросный лист содержит шесть вопросов, предполагающих ответы в свободной форме. Последовав совету социолога Э. Хаммонда, мы не стали ограничивать респондентов конкретными формами и примерами ответов, что позволило добиться более открытого и точного выражения ими своей точки зрения. Подобный метод опроса, по его словам, «незаменим в гуманитарной сфере, предполагающей соприкосновение с областью эмпирического, потенциально содержащей множество инвариантов восприятия конкретного объекта искусства» [Хаммонд, 2010, с. 11-14].

Мы поставили себе задачу выявить и наиболее ранний возраст читателей романа, который, по утверждению булгаковеда М. Чудаковой, «благодаря полифоничности и многоуровневости доступен для понимания, начиная с третьего класса средней школы» [Чудакова, 2002, с. 37].

Итак, примерно 40\% респондентов указали, что впервые познакомились с романом до 18-ти лет, (некоторые из них - в 10-12 лет по совету друзей и родственников). Подавляющее большинство отмечают, что не единожды возвращались к роману в более позднем возрасте. Нужно констатировать, что читатели разделились на две группы. К первым относятся те, кому роман понравился сразу, несмотря на то, что они, по собственному их признанию, многого не поняли. В этом отношении нельзя не вспомнить утверждение булгаковеда Соколова: «Он (роман) срабатывает с первых же страниц, и не важно, чему он учит и о чем рассказывает. Главное - в атмосфере, в том удивительном, пленительном микрокосме, мире вещей и явлений волшебства, который остается с вами на всю жизнь...» [Соколов, 2004, c. 84].

Иные признаются, что при первом прочтении не вникли в суть, и потому в течение долгого времени не могли заставить себя перечитать книгу. По словам, психолога Е. Науменко, «фактор литературного впечатления не объясняется исключительно художественными достоинствами того или иного произведения. На него проецируются также сопутствующие элементы: самочувствие человека в момент общения с книгой, жизненные обстоятельства, наконец, погода за окном...» [Науменко, 2002, с.19] Так, респондентка Е. Морозова пишет: «Впервые роман произвел на меня неприятное впечатление. Правда, читала я его, находясь в больнице. Меня готовили к операции. Все эти коты, ведьмы, вампиры... - достаточно угнетающая тема. Вряд ли я еще когда-нибудь к нему вернусь!». Сравнительно незначительное число читателей (всего примерно 3\% от общего числа) не собирается возвращаться к тексту.

Среди участников нашего опроса нашлись те, кто солидарен с тем мнением, что роман «Мастер и Маргарита» является детским: «Роман сродни рассказам о Гарри Поттере и рассчитан на подростковую аудиторию» (читатель О. Конанов, 32 года).

Действительно, младшие участники исследования (до 18-ти лет) отмечают, прежде всего, авантюрные и плутовские аспекты его сюжета, связанные с мотивами преследования, погони, быстрого движения и проделками свиты Воланда. «Никогда не забуду погони Ивана за свитой Воланда по ночной Москве, а также полета Маргариты на реку. Это самая волшебная из сказок, потому что похожа на реальную жизнь», - пишет пятнадцатилетняя девушка. «Крутизна Воланда и его свиты не оставила меня равнодушным», - отмечает ученик девятого класса средней школы. Подростки, как правило, не делают различия между образами Воланда и его свиты, тогда как для более старших читателей это различие - очевидно, и для них свита Воланда носит вспомогательный, шутовской, трикстерский характер, тогда как самому Воланду отводится более серьезная роль. Впрочем, к этому вопросу мы вернемся чуть позднее.

Очевидно, юные читатели симпатизируют именно авантюрно-мистическому колориту произведения («ведьмы, праздник, мазь... - нечисть... - вот для меня Булгаков», - М. Тищенко, 17 лет). Зачастую в качестве наиболее близких и сим- 
патичных героев они указывают именно Воланда и его свиту. Для подростков они сродни волшебникам, способным творить чудеса. Аналогии с «Гарри Поттером» очевидны. Опыт показал, что подростки не делают акцента ни на социальной сатире, ни на очевидном для более старшего поколения политическом подтексте. «Больше всего мне запомнился сеанс черной магии в Варьете, а также хоровое пение работников. Жаль, что в нашем цирке не делают таких фокусов», - пишет Антонов Влад, ученик 7-го класса. Исследователь психологии восприятия художественного текста подростками В. Степанов замечает: «Юный читатель всегда находится в центре событий. Он всегда на коне, с ярким факелом, пронзающим ледяную тьму и мечом в серебряных ножнах, всегда готов к приключениям и опасности. Он сам - причина всему. Для него так естественно отождествление себя с избранными героями» [Степанов, 1999, с. 31].

В качестве наиболее близкого образа выделяют прежде всего Маргариту (среди младшей категории - в подавляющем большинстве девочки - подростки, ставящие ее в один ряд с пушкинской Татьяной Лариной), Мастера (как «одинокого изгнанника, подобного байроновским романтическим героям», О. Киприлова, 17 лет), а также членов свиты Воланда. Например, «Бегемот - самый прикольный из литературных персонажей, Коровьев - милашка», - отозвалась о героях Булгакова ученица 9-го класса, Е. Маркасова. В качестве героев, достойных сочувствия, юные читатели снова называли Маргариту (опять же в основном - женская половина), Римского («Не очень-то приятно, когда ведьма лезет в окно»), Берлиоза («жестокая смерть под трамваем»). Любопытную мысль высказала ученица 9-го класса Ю. Сидоренко: «Самая интересная сказка - та, которая не похожа на сказку. Фантастика Булгакова выглядит столь похожей на правду, что хочется верить в чудеса». В числе своих любимых авторов девушка назвала С. Лукьяненко, В. Пелевина, т. е. современных писателей-фантастов, умело соединяющих жанр городской повести с элементом фантастики. Так что роман Булгакова воспринимается на фоне опыта чтения «городского фэнтези», основными приметами которого журналист О. Плотников называет «тесное соседство привычной нашему глазу реальности и элементов безудержной авторской фантазии» [Плотников, 2010, с. 25-26].

Беседа со школьными учителями показала, что многие подростки не в состоянии полноценно воспринять роман из-за сложности языка. Типичный отзыв: «Нет, перечитывать не собираюсь. Язык не слишком понравился, я не понимаю его» (О. Темерязев, 11 класс). Очевидно, что на фоне богатого выбора фантастической литературы, заполнившей сегодня прилавки книжных магазинов, роман кажется слишком сложным, так как принадлежит к ушедшей в прошлое политической и культурно-исторической эпохе, а потому требует большого количества комментариев. Тот же мистическо-фантастический элемент, столь редкий и привлекательный для читателей советской и постсоветской эпохи, нынче представлен юношеской литературой в изобилии (Толкиен, Лукьяненко, Пелевин и др.), социально-исторический, фельетонный контекст, напротив, мало интересен, далек от современности. «Самый нудный - это рассказ о Никаноре Ивановиче, к чему он? Не понимаю, как такой большой писатель как М. Булгаков мог сочинить такое?»заявил недавний выпускник средней школы, А. Самойленко. Очевидно, что с уходом социального контекста многие фрагменты романа теряют в глазах молодых читателей свою остроту и актуальность. История литературы знала ни один подобный пример. Однако, по мнению Б. Соколова, булгаковский роман «спасает мощный духовный заряд, по определению выходящий за рамки любой эпохи...» [Соколов, 2004, с. 87].

Неординарная, двойственная структура произведения также воспринимается двояко. «Я никогда не понимала, зачем приплетена часть про Иешуа», - призналась одна из респонденток. По замечанию школьного учителя В. Савченко, дети с трудом воспринимают «пилатовы главы» ввиду недостаточной культурно- 
исторческой подготовки и слабой вовлеченности в религиозные тексты и практики: «К чему этот Понтий Пилат?» (А. Северинова, 9 класс).

В основном читатели подчеркивают нетипичность, уникальность и оригинальность Булгакова как писателя. («Я ассоциирую Булгакова с Булгаковым, и ни с кем больше!») - около 30\% анкет. Впрочем, многие отмечают также Н. Гоголя, подкрепляя свою точку зрения «мистичностью» обоих литераторов и ссылкой на то, что сам Михаил Афанасьевич считал Гоголя своим учителем. Дважды был упомянут Л. Андреев. Также в отдельных случаях были названы Л. Толстой, Ф. Достоевский, И. Бунин. А. Акопян, специалист в области психологии литературных ассоциаций, полагает, что «количество таковых обратно пропорционально уровню освоения базового произведения. То есть, чем серьезнее и глубже восприятие, тем более независимым, самобытным предстает каждый текст» [Акопян, 2009, с. 64-66]. Результаты нашего опроса показали, что среди реципиентов старшего поколения больше тех, кто не допускает однозначной ассоциации М. Булгакова с иными деятелями литературы.

Читатели старшего возраста (18-45 лет) дифференцировали собственные ассоциации по различным основаниям. Например, мнение В. Трофимовой (28 лет): «В мистике - Гоголь, Андреев, соц. реализм - Мандельштам, Пастернак, Гумилев, юмор, приключения - братья Вайнеры». Надо отметить, что среди мужчин в возрасте 18-45 лет очень популярно сравнение М. Булгакова с В. Пелевиным. Причем, в отличие от школьников, отмечающих в основном авантюрно-трикстерский элемент, взрослые говорят об острой социальной сатире. Так, студент-социолог Ю. Брежнев сравнил «Мастера и Маргариту» с рассказом В. Пелевина «Проблема верволка в средней полосе России»: «Зооморфизм, как прием, к которому прибегают оба автора, в обоих случаях позволяет иносказательно говорить о человеческих пороках. Правда, тут неизвестно, кто в большей степени - животное: булгаковский Бегемот или пелевинская стая оборотней».

Результаты опроса средней возрастной категории оказались более разнообразными. Отметим наиболее существенное.

К 30-летнему возрасту более $40 \%$ процентов опрошенных перечитали роман три раза и более. Около $20 \%$ процентов респондентов регулярно перечитывают произведение. На вопрос «почему?» были получены следующие ответы: «Каждый раз воспринимаю по-разному»; «чтобы лучше понять»; «нравится погружаться в атмосферу романа»; «он вечен»; «вселяет жизнь» - такого рода ответы показывают, что для читателей во многом важна именно эмоциональная окраска. Однако были и чисто «рациональные» ответы: «Не хотел бы его перечитывать, так как там сбор давно известных истин»; «перечитала бы только из интереса к бытовой стороне: как люди одевались, куда отдыхать ездили, каковы были бытовые приборы...». И, конечно же, были курьезные ответы: А. Семенченко, 29 лет: «Перечитал бы, только не главы о Понтии Пилате. Они - нудные!».

Многие отметили Воланда в качестве близкого им героя, «в котором остро нуждается наше время и наша страна...» (И.Е. Рыбникова, 71 год). На вопрос о причине подобного выбора отвечали по-разному. Были и такие высказывания: «Хотелось своими руками уничтожить мелких московских пройдох и жуликов. Также поражает остроумие Воланда и его свиты» или «На фоне всех остальных Воланд - единственный разумный персонаж». В развернутых отзывах люди замечают, что им хотелось бы, «чтобы Воланд посетил их город, дабы приструнить некоторых чиновников». Среди старшего поколения читателей по сей день встречаются те, кто видит в образе Воланда Сталина, способного покарать зло злом. «В современности не сыщешь прототипа мессиру, которого автор явно писал со Сталина. Ни в ком более нет той мощи, необходимой для поддержания порядка». Или «Воландовская проницательность - комплимент писателя Сталину», - убеждена читательница О. Морозова (67 лет). Таким образом, Воланд предстает героем, вершащим высший суд и возмездие. Впрочем, и среди молодых читателей 
встречаются те, кому близок Воланд и его свита, «справедливо вершащие суд над обществом, пропащим человеческим родом, что в принципе привлекательно для человека, осознающего собственное несовершенство, и желающего борьбы с ним» (А. Кольченко, 21 год). Эти предпочтения отражают эволюцию авторского замысла романа, смещение его центра от первоначального романа «о дьяволе» к роману о мастере и его возлюбленной. Думаем, здесь нелишним будет обратиться к мнению исследователя в области рецептивной эстетики Х-Р. Яусса: «Читатель, хочет он того или нет, неосознанно переносит на воспринимаемый текст реалии собственной жизни. Причем, приметы времени в этом случае становятся орудием в его руках, а художественный текст, будь он написан хоть в позапрошлом веке, - ответом на самые насущные вопросы» [Яусс]. Налицо тот факт, что человек «ждет» от свиты Воланда решения проблем современности.

Иешуа и Мастер заняли почетное второе место по количеству «почитателей». В качестве аргументов их значения приводятся «стремление бороться за справедливость, человеколюбие, свободу творчества». Довольно показательно, что Мастер пользуется большой популярностью у представителей творческих профессий. Из авторов 35 анкет (заполненных музыкантами, поэтами, художниками) 26 - отметили Мастера в качестве наиболее близкого героя. Однако далеко не все из них заявили о своем сочувствии ему. Сочувствуют в основном Маргарите, Берлиозу («он, конечно, сноб, но не под трамвай же его из-за этого», - пишет А. Якимович, 34 года). В четырех анкетах данной возрастной категории в числе прочих персон, достойных сочувствия, назван дядя Берлиоза, а также буфетчик Соков. Одна женщина призналась, что сочувствует Маргарите только по причине того, что та «живет с нелюбимым мужем, и терпит серость повседневности». Интересно, что буквально на следующий день мы получили анкету, где было написано следующее: «Больше всего сочувствую брошенному мужу Маргариты. Никакому мужику не пожелал бы такого позора» (В. Дроздов, 29 лет).

Примерно каждый пятый опрошенный, достигший 18-ти лет, признался в сочувствии Понтию Пилату. «Угрызения совести, борьба с самим собой, жестокая социально-политическая действительность»; «Нет ничего хуже, чем вечные угрызения совести»; «Человек, испытавший весь ужас выбора между человечностью и социально-политической необходимостью. Врагу не пожелаешь!»; «Жалкий человек, осознающий свою слабость, бессильный пойти против беса в себе». Возвращаясь к теории Х-Р. Яусса, нельзя не согласиться с тем, что «каждому человеку в тексте видится его личный мир, достраивается и моделируется его же сознанием».

«Какой пласт романа наиболее Вам близок?», - таков был четвертый вопрос опросного листа. В отличие от младшей возрастной группы, предпочитающей мистический и фантастический аспекты произведения, средняя и старшая группа избрала «морально-этический». Читатели верят в то, что «горькая булгаковская сатира способна заставить общество и каждого отдельно взятого человека задуматься об избранном образе жизни, зачастую исключающем элементарную честность и благородство» (Т. Оскорбина, 34 года). Что касается «религиозного пласта», то по сравнению с концом 80-х - 90-ми годами его «популярность» среди читателей несколько снизилась. Предполагаем, это связано с повсеместным распространением знаний о христианстве и его текстов, утратой запретности, а значит и былой остроты. Даже представители церкви с некоторых пор сняли табу на роман в связи с тем, что «авантюрная и сатирическая направленность его, несомненно, является определяющей... <..> Вместе с тем история о бродячем философе Иешуа не имеет никакого отношения к каноническому Евангелию. Это просто художественное произведение, прежде всего, сатирической направленности», - считает известный богослов А. Кураев [Кураев, 1999, с. 25]. В связи с этой темой примечательно и такое мнение: «Мистичность романа привлекательна для тех, кто убил в себе религиозность» (В. Трофимова, 28 лет). Скорее, речь идет 
о еще не оформившейся религиозности, характерной для младшей аудитории. По признанию половины опрошенных, наблюдается четкая тенденция с возрастом утрачивать интерес к авантюрному / фантастическому / мистическому слою, и все больше обращаться к морально-этическому / религиозному, а также общественноисторическому аспектам.

Пятым пунктом нашей анкеты стал вопрос о том, изменилось ли читательское восприятие романа в связи с изменением общественно-политического строя в России на рубеже 1980-х - 1990-х годов? Однако среди представителей средней возрастной категории (18-45 лет) не нашлось людей, давших положительный ответ. Читатели отмечают, что «восприятие изменяется, прежде всего, с возрастом, с жизненным опытом, тогда как государственные режимы здесь вовсе не причем (И. Зензина, 39 лет). «Восприятие в принципе не может зависеть от режима», отметила В. Трофимова. Известный новосибирский поэт и музыкант А. Костюшкин (41 год) написал: «Такие произведения выше общественнополитических строев!». Частными суждениями, (но не менее важными!) можно считать такие, как «восприятие изменилось в первую очередь с развитием кинематографа» (Ст. Заречанский, 36 лет) или «...изменилось с открытием (для себя!) Книги Священного Писания» (А. Панчев, 32 года).

Некоторые реципиенты (примерно 20\% от общего числа) предпочитали давать более полные ответы, как то: «...с возрастом мое восприятие романа изменилось в худшую сторону, так как я поняла, сколько опасных иллюзий он сеет в сознании человека, особенно - юного» или, напротив: «Лишь годы спустя я оценила глубокий философский смысл произведения, облеченный в авантюрную форму».

Таким образом, нами были сделаны следующие выводы:

Роман М.А. Булгакова по-прежнему очень популярен среди российской читательской аудитории. Возраст читателей - от 10 лет и старше. Акценты в интерпретации романа значительно разнятся в зависимости от возраста конкретного реципиента. Наряду с этим они сильно зависимы от хода общего исторического процесса.

Большой процент опрошенных отдает предпочтение какому-либо конкретному смысловому пласту романа. Причем, зачастую с возрастом это предпочтение изменяется.

Отношение к роману в основном не зависит от актуального политического режима в стране.

Подавляющее большинство респондентов признается в том, что для них ведущим является эмоциональный (эмпирический) тип восприятия романа. («Не могу сказать, чем именно, но нравится мне, безумно!») Примерно треть - обнаружили чисто рациональный подход к произведению. («Нравится, потому что другое, незнакомое, время, интересен способ мышления героев, взаимоотношения представителей советской эпохи» и т. п.).

Выявлена небольшая группа читателей, заинтересованных какой-то конкретной стороной романа. («Признаюсь честно, меня интересует только сатира на советские реалии. Больше там нечего ловить!» - А. Кипарисов, 32 года; «Главное великая повесть о Иешуа. Авторское виденье Евангелия. Остальное - лишь огранка» - Л. Алехина, 45 лет) и т. п.

\section{Литература}

Акопян А. От Ломоносова до Пелевина. Опыт работы с материалами литературных ассоциаций // Литературная газета. 2009. Вып. 8. С. 64-66.

Кураев А:М. Булгаков: за Христа или против? М., 1999.

Науменко Е. Психология чтения. СПб., 2002.

Плотников О. Слово о Гарри Поттере // Теленеделя. 2010. Вып. 11. С. 25-26.

Соколов Б. Тайный Булгаков. М, 2004. 
Степанов В. К вопросу о юношеском восприятии художественного текста // Психология и жизнь. 1999. Вып. 8. С. 11-17.

Хаммонд Э. Социология и муза. Ступая по зыбкой грани // Вопр. психологии 2010. Вып. 4. С. 11-14.

Чудакова М. Воспоминания о Михаиле Булгакове. М., 2002.

Яусс Х-Р. История литературы как провокация [Электронный ресурс]. Режим доступа

http://www.libok.net/writer/14437/kniga/62670/yauss_hans_robert/istoriya_literaturyi_ kak_provokatsiya/read. Дата обращения - 25.02.2013. 